\title{
Examining the Origins of Hafting in South Asia
}

\section{J. Blinkhorn ${ }^{1,2}$}

Published online: 13 July 2019

(C) The Author(s) 2019

\begin{abstract}
The appearance of hafting technologies marks a key shift in hominin behavioural evolution. Hafting first appears in Africa and Western Eurasia across the transition from Late Acheulean to Middle Palaeolithic technologies 300-200 thousand years ago (ka). Hafting technology in South Asia may have emerged as a result of a local innovation, through cultural diffusion or a population dispersal. The resolution of the South Asian Palaeolithic records has improved significantly over the past decade, enabling examination of patterns of change through time in stone tool technologies. Although functional studies of tool use remain limited in the region, a range of indices of hafting appear in stone tool assemblages that offer the first means to evaluate the origins of hafting in South Asia. Rare examples appear in Middle Pleistocene contexts, but indices of hafting appear repeatedly in Middle Palaeolithic assemblages dating within the past 100 thousand years and are commonplace amongst Late Palaeolithic assemblages dating within the past 45 thousand years. This dataset remains too immature to authoritatively resolve between alternate models for the origins of hafting, whereas direct association with discrete hominin populations is hampered by the region's scant fossil record. Nevertheless, this examination of the origin of hafting technology presents the means to reorient approaches to Late Pleistocene behavioural change in South Asia and integrate them within global debates regarding hominin innovation, demographic interaction and population expansion.
\end{abstract}

Keywords Hafting technology $\cdot$ Stone tools $\cdot$ South Asia $\cdot$ Innovation $\cdot$ Human dispersal

\section{Introduction}

The transition from sole use of hand-held tools to incorporation of hafted technology, such as stone-tipped spears, marks one of the most profound changes in the long-term

\section{J. Blinkhorn}

james.blinkhorn@rhul.ac.uk

1 Department of Geography, Royal Holloway, University of London, Egham, Surrey, UK

2 Department of Archaeology, Max Planck Institute for the Science of Human History, Jena, Germany 
evolution of human behaviour. Creating hafted tools is more complex than hand-held tools alone, requiring more diverse components, a mastery of their physical properties and more recursive and hierarchical forms of cognition to integrate them into a single tool (Fairlie and Barham 2016). This cognitive and technological investment enables new and more efficient ways of using stone tools, mitigating subsistence risk, engaging with ecological resources and mediating social relationships (d'Errico and Banks 2013). An ever-increasing number of non-human species exhibit cultural transmission of tool use (Shumaker et al. 2011), yet only hominin populations from the late Middle Pleistocene onwards are known to produce hafted technologies.

The earliest evidence for hafting, though controversial, comes from Kathu Pan, Southern Africa, dating to 500 thousand years ago (ka) (Wilkins et al. 2012; Wilkins and Schoville 2016; see also Rots and Plisson 2014). This significantly predates the appearance of Homo sapiens in Africa, currently known from $300 \mathrm{ka}$ (Hublin et al. 2017). A range of direct evidence for hafting is found dating from Marine Isotope Stage (MIS) 7/8 in Africa (e.g. Rots and Van Peer 2006), the Levant (e.g. Boëda et al. 2008; Shea 1993) and Europe (e.g. Mazza et al. 2006; Rots 2013). Given the spatially disjunct manner of the earliest evidence for hafting alongside its association with multiple hominin populations, it remains likely that hafting technologies are a convergent feature of hominin behaviour in the later Middle Pleistocene onwards, with multiple centres of origin (Barham 2013). It is notable that the potential centres for the origins of hafting also overlap regions in which a local evolution of Middle Palaeolithic/Stone Age technologies from Late Acheulean antecedents occurs.

The most secure evidence for Palaeolithic hafting results from studies that can directly demonstrate its use in the past, through the recovery of mastics from stone tools used in hafting (e.g. Mazza et al. 2006), through microwear on stone tools relating to distinct patterns of abrasion where it has been hafted or used (e.g. Rots and Plisson 2014) and through impact fracture patterns that can only be produced from hafted tools (e.g. Wilkins et al. 2012). Such work remains predominately focused in regions that combine a rich Palaeolithic record, an array of sites that limit the potential for destructive taphonomic factors, and where research agendas enable the highly specialised and time-consuming analyses and methodological development required, such as Europe. More recently, the application of such methods can has begun in geographically diverse regions (e.g. Pawlik 2011).

In multiple regions, stone tool morphologies have been used as indirect evidence for the presence of hafting technologies in Palaeolithic assemblages. A prominent example of this is North Africa where Aterian assemblages are differentiated from Mousterian assemblages by the presence of tanged points, which have historically been presumed to have facilitated hafting (e.g. Clark 1982). Alongside tangs, a range of morphological adjustments have been associated with hafting, including basal thinning and width reduction, removal of bulbs, notching, shouldering and backing (see Rots 2016). Amongst younger assemblages, standardisation of blanks or retouched pieces and the production of microliths have been proposed as technological choices to facilitate hafting and particularly multi-component hafted tools (e.g. Bar-Yosef and Kuhn 1999). Without direct studies for Palaeolithic hafting, and particularly focusing on elements of stone tools that were formed part of the haft or were active working edges, such morphological indicators along cannot provide robust evidence for the presence of hafting (Rots 2016). However, in regions where direct evidence for hafting is not 
currently available, such morphological adjustments to stone tools offer an important starting point to evaluate the appearance of hafting. For example, a recent study of tanged Aterian points from Ifri n'Amar has corroborated their use as hafted tools (Tomasso and Rots 2018).

To date, no systematic studies, such as use-wear or residue analysis, have been undertaken to examine the origins of hafting in South Asia during the Palaeolithic. Systematic use-wear studies accompanied by an experimental programme have been undertaken on Mesolithic assemblages at the site of Bagor (Rajasthan, India) that date between 7 and $5 \mathrm{ka}$ (Kashyap et al. 2009). This has identified two triangles with impact damage that was comparable with experimental evidence for use as a projectile point. Much of South Asia's rock art is considered to have been produced by hunter-gatherer populations, including sites with Late Pleistocene occupations (e.g. Jwalapuram 9 [Clarkson et al. 2009]). Numerous images suggest the presence of hafted tools, and especially the use of microlithic tools as hafting inserts for multi-component tools (e.g. Mathpal 1985), though accurately dating such imagery is notoriously complex. Ethnoarchaeological studies of stone tool use amongst recent populations are similarly limited. However, Murty $(1981,1985)$ highlights the use of resins from three species (Acacia sandra; Dalbergia paniculata; Excoecaria agallocha) as mastics by recent Chencu populations. It is notable that plant resins, such as those from Acacia that are distributed across Africa and Southern Asia, have a history of use as mastics that extends back to the Middle Palaeolithic (Zipkin et al. 2014).

Until recently, there has been an absence of well-dated Palaeolithic sites from the late Middle Pleistocene and early Late Pleistocene in South Asia, in contrast to other regions where the emergence of hafting technologies is documented. Over the past decade, the Palaeolithic record of South Asia, and particularly for the Late Acheulean and early Middle Palaeolithic phases, has been dramatically transformed (see Blinkhorn and Petraglia 2017) that enables new questions to begin to be addressed. The absence of functional studies of hafting in the South Asian Palaeolithic prohibits a firm assessment of the origins of these technologies in the region. However, an appraisal of existing indices of hafting is particularly timely as the chronology and nature of the Late Acheulean to Middle Palaeolithic transition comes into focus. The aim of this paper is to set out alternate models for the origins of hafting in South Asia and evaluate them against the currently available evidence. Given the absence of direct studies to identify Palaeolithic hafting in South Asia, any conclusions on its origins in the region are inherently tentative, but this study will highlight how this major technological change sits squarely at the crux of wider debate over patterns of innovation, creativity, colonisation and expansion, and thus the importance of applying such advanced methodologies in the region.

\section{Models for Behavioural Change in South Asia}

Three explanations can be proposed for the appearance of any new cultural trait (see Fort et al. 2015): (a) independent innovation by local populations; (b) introduction through cultural diffusion, i.e. information exchange between populations in adjacent regions; or (c) introduction through demic diffusion, i.e. population expansion into new regions. All three are plausible explanations for the origins of hafting in South Asia but have dramatically different implications for our understanding of cultural evolution in the region. 
South Asia may present an independent centre for the innovation of hafting. As noted above, the region shares a common Acheulean background with Southern Africa, Eastern Africa, the Levant and Southern Europe, from which hafting appears an independent innovation associated with the appearance of other Middle Palaeolithic/ Stone Age technologies (Barham 2013). If South Asia were an additional independent centre for the innovation of hafting, we may anticipate continuous occupation of the region with little or no contact with adjacent regions, and the appearance of hafting technology occurring as part of a gradual transition from Late Acheulean to Middle Palaeolithic industries. We may anticipate some parallels in patterns of cultural evolution from Late Acheulean to Middle Palaeolithic technologies with other regions in which hafting was independently innovated, including the development of Levallois technology, replacement of larger bifacial tools with smaller retouched tools and increased focus on higher quality raw materials. The paucity of South Asia's Quaternary fossil record, and especially with any association with hominin activity, prohibits any evaluation of patterns of change in subsistence practice. While patterns of site distribution and location may be indicative of changing use of the landscape and the resources within it, the relatively small number of dated Palaeolithic sites prevents a high-resolution appraisal of such changes.

Identifying cultural diffusion between past populations is complex, and reliant upon sufficiently well-dated cultural and biological datasets. Europe presents some of the clearest examples of Palaeolithic cultural diffusion (Harris 2017), with the Chatelperronian industry as a long-standing example of such diffusion between distinct hominin populations (though see Higham et al. 2010). If cultural diffusion were responsible for the appearance of hafting in South Asia, it is most likely to have resulted from contact with South-West Asian populations, given the early appearance of hafting in this region contrasting with its arrival in East Asia alongside modern human populations (Barham 2013).

Hafting technology is complex, requiring expertise in working with a number of different materials as well as to effectively integrate them to create a single tool. As a result, chance or fleeting encounters with another population are unlikely to have enabled the transfer of such expert knowledge to practice hafting, compounded by the risk of subsistence failure if the implementation of such knowledge is not done effectively. Rather, cultural diffusion of hafting technology is more likely to arise from repeated contacts between two populations sharing landscapes with similar resource suites. Such a process may be manifested in the archaeological and fossil record as a distinct cline in space and time of evidence of hafting as well as patterns of interbreeding from South-West Asia into South Asia.

Finally, hafting technologies may have been introduced by the replacement of local South Asian populations that do not practice hafting by an external population that do. Currently, the only clear evidence for an invasive hominin population spreading into South Asia is the dispersal of modern humans (e.g. Bae et al. 2017). Modern human populations are associated with the use of hafted tools in Africa and South-West Asia, as well as in earliest assemblages in well-studied regions such as Europe, where their use is likely to play a key role in successful colonisation of new landscapes (e.g. Pawlik 2011). Hafted tools may confer a competitive advantage to an invasive population in cases where local populations lacked them, although the extent of this is likely to be constrained by the additional requirements for more intensive landscape learning to find the required 
resources necessary for hafting. Archaeologically, the appearance of hafting in South Asia as a result of population dispersal would likely be manifest as a rapid replacement of technologies not associated with hafting technologies with those that are.

Considerable overlap between these models for the origins of hafting in South Asia and those concerning the dispersals of modern humans exists. Until recently, models suggesting the earliest dispersals of modern humans $\sim 60 \mathrm{ka}$ associated with the appearance of Late Palaeolithic technologies in South Asia were tenable (Mellars et al. 2013; Mishra et al. 2013), if poorly supported (Blinkhorn and Petraglia 2017; Groucutt et al. 2015). A growing body of inter-regional evidence supports the dispersal of modern humans across Asia significantly earlier than the appearance of Late Palaeolithic technologies, suggesting that they are not related to the earliest expansion of our species into the region (Bae et al. 2017). It is worth noting, however, the emphasis that has been placed on backed artefacts, assumed to have been used as standardised inserts in multi-component hafted tools and associated with advanced projectile technologies, in facilitating the expansions of modern humans to the detriment of local populations in these models.

As it is now apparent that the arrival of modern humans in South Asia likely precedes the origins of Late Palaeolithic technologies in the region, two alternate scenarios for their impact on cultural evolution in the region can be proposed. Firstly, eastward expanding modern human populations utilising Middle Palaeolithic toolkits replaced a local population, also using Middle Palaeolithic technologies. As a result, patterns of cultural evolution may reflect a similar pattern to those in the Levant, where population replacements are observed between distinct populations, i.e. Neanderthals and modern humans, both of which used Middle Palaeolithic technologies. Alternatively, modern human populations using Middle Palaeolithic toolkits replaced local, South Asian populations that used Late Acheulean technologies.

\section{Palaeolithic Demography in South Asia}

Patterns of demographic change are poorly resolved in South Asia, due to a significant gap between the only pre-sapiens fossil, dating to $236 \mathrm{ka}$ (Patnaik et al. 2009), and the earliest Homo sapiens, dating to $\sim 36 \mathrm{ka}$ (Perera et al. 2011). A study of the calvarium from Hathnora, best attributed to Middle Pleistocene Homo and associated with Late Acheulean industries, indicates it shares a similar cranial capacity to contemporaneous populations that did innovate hafting technology (Athreya 2015). The links between cranial capacity, cognitive ability and material behaviour are not direct, but a local innovation of hafting cannot not be precluded from South Asia's scant fossil record. The specimen exhibits characteristics shared with both Eastern and Western Eurasian populations (Athreya 2015), potentially indicating long-standing patterns of interbreeding spanning Southern Asia. This could offer some tentative support to the prospect of cultural diffusion playing a role in the regional origin of hafting.

Fossil evidence for the appearance of Homo sapiens in Sri Lanka ( $36 \mathrm{ka}$ [Perera et al. 2011]) and India (20 ka [Clarkson et al. 2009]), found alongside Late Palaeolithic industries, significantly post-dates the dispersal of modern humans across Southern Asia (130-67 ka; Demeter et al. 2012; Grun et al. 2005; Liu et al. 2015) and into Sahul (80$65 \mathrm{ka}$; Clarkson et al. 2017). This has led to considerable debate about when modern 
humans arrived in South Asia and speculation regarding authorship of Middle Palaeolithic industries. Typically, population and technological continuity have been emphasised between the Late Acheulean and Middle Palaeolithic (e.g. Mishra et al. 2013). Over the past decade, it has been repeatedly proposed that modern human populations used Middle Palaeolithic industries in their earliest dispersals from Africa and into South Asia (e.g. Groucutt et al. 2015; Petraglia et al. 2007). An alternative is that the Middle Palaeolithic in South Asia could have been produced by more than one population (e.g. Kaifu et al. 2015). At present, there is no evidence to support a third Late Pleistocene hominin occupant in South Asia.

\section{Cultural Evolution in South Asia}

Within the past decade, a clear chronological framework for cultural evolution in South Asia has come in to focus (see Blinkhorn and Petraglia 2017). Unlike Africa and Western Eurasia, Late Acheulean industries in South Asia persist until the end of MIS $6 \sim 130$ ka (Haslam et al. 2011). Evidence for change amongst Late Acheulean assemblages indicates increasingly refined biface production, with detailed study of the youngest assemblages indicating the appearance of discrete components of Levallois reduction strategies, such as hierarchical exploitation of a flaking surface (Shipton et al. 2013; Shipton 2016).

The earliest Middle Palaeolithic (or Middle Stone Age) assemblage in the world has been reported from Attirampakam, South-East India, dating to $\sim 385 \mathrm{ka}$ (Akhilesh et al. 2018), although significant chronological breaks occur in the sequence and before these industries are found anywhere else in South Asia. Middle Palaeolithic industries appear repeatedly in the second half of MIS 5, from 96 ka (Blinkhorn et al. 2013, 2017), marking a 30-ka gap from the youngest well-dated Late Acheulean industries (see Blinkhorn and Petraglia 2017). Substantial chronological breaks in the archaeological record mean it remains unclear whether the shift to using typically Middle Palaeolithic strategies, such as Levallois technologies, diversification of raw material use, decrease in artefact size and increase variability in retouched tool types, marks a rapid or gradual change. Middle Palaeolithic assemblages that continue into the later phase of MIS 3 ( $34 \mathrm{ka})$ show further decreases in artefact sizes, the rising prominence of both blade technologies and the first appearance of bipolar reduction (Blinkhorn 2014; Clarkson et al. 2012).

Substantial spatial, temporal and technological overlap is observed between the youngest Middle Palaeolithic and oldest Late Palaeolithic industries in South Asia (see Blinkhorn and Petraglia 2017), with the latter emerging from 45 ka onwards (Mishra et al. 2013; Basak et al. 2014; Wedage et al. 2019). Continued trends from the Middle to Late Palaeolithic include further decrease in artefact sizes and increased focus on blade a bipolar reduction, whereas prepared core methods decline in frequency and microlithic tools replace typical Middle Palaeolithic retouched types (Clarkson et al. 2012; Sali 1989; James 2011).

\section{Identifying Hafting in South Asia}

The advances in dating of Late Pleistocene Palaeolithic assemblages now enable an appraisal for the origins of hafting in South Asia. Barham (2013) presents a hierarchy of certainty for identifying hafting in the archaeological record. Use-wear and residue studies, 
complemented by experimental analyses, offer the firmest grounds to identify hafting in the past. This includes identifying the presence of mastics (e.g. Zipkin et al. 2014), patterns of microwear located either at the functional edge of an artefact or within the haft itself (e.g. Tomasso and Rots 2018) or the identification of diagnostic impact fractures, a set of microfracture types formed through bending and cone-initiated impacts forces typically associated with hafted tool use (see Lombard 2005). To date, only a single systematic study has employed such methods in South Asia with the support of an experimental programme, though targeting Mesolithic assemblages (Kashyap et al. 2009).

Macroscopic modifications of artefacts that have been widely linked with hafting practices are more commonplace but offer less certain grounds to identify their use. Types of macroscopic modification include backing (applying regular abrupt or steep retouch along an edge), creating a shoulder (a form of delineating retouch that cuts into the edge of the artefact, narrowing it at one extremity) or creating a tang (a form of delineating retouch, creating a projection narrower than the body of the artefact by two flanking notches or regular retouch removals) (see Inizan et al. 1992). The production of standardised stone points, comparable to hafted implements well known in ethnographic records, is frequently identified as hafted tool tips, though provides low level of certainty than the types described above. Standardisation of point production may result from either controlled shaping of a flaking surface to produce blanks of predetermined shape and size and can thus be identified by either the core or the blanks (e.g. Levallois point technologies), or through the application of retouch to the perimeter of a flake to create, accentuate or standardise tool. A metric study has compared the size range of Middle Palaeolithic points to ethnographic data sets, suggesting they predominately overlap with thrusting spears, although artefacts in the range of projectiles were also identified (Costa 2012). As further resolution between these alternatives can only be achieved through the application of functional studies, such data are not considered here. The appearance of these different indices of hafting behaviour in Palaeolithic South Asia in dated assemblages are presented through time (Fig. 1) and space (Fig. 2) and are described below.

\section{Diagnostic Impact Fractures and Mastic Use}

No comprehensive use-wear or residue analysis studies have been conducted on South Asian Palaeolithic industries to date. However, preliminary observations have been made on Middle and Late Palaeolithic artefacts from the Jurreru Valley, Southern India, as well as a report of ongoing functional studies at Fa Hien, Sri Lanka. Two Middle Palaeolithic points from the site of Jwalapuram 22, dating to $\sim 77 \mathrm{ka}$, have impact fractures on their tips that would be consistent with their use as hafted tools (Haslam et al. 2012; Fig. 3b). Identification of a resinous mastic on backed Late Palaeolithic artefacts from Jwalapuram 9, which appear from $\sim 35$ ka onwards, currently offers the most secure evidence of hafting across South Asia (Clarkson et al. 2009). In both cases, further experimental studies and detailed analysis are necessary. At Fa Hien, four of five bone points dating to $\sim 45 \mathrm{ka}$ exhibit damage consistent with high velocity impact through the use of projectile technology (Wedage et al. 2019), with ongoing study of both the bone and stone tool assemblages aiming to document this further. 


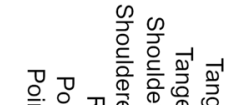

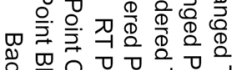

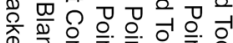

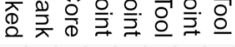

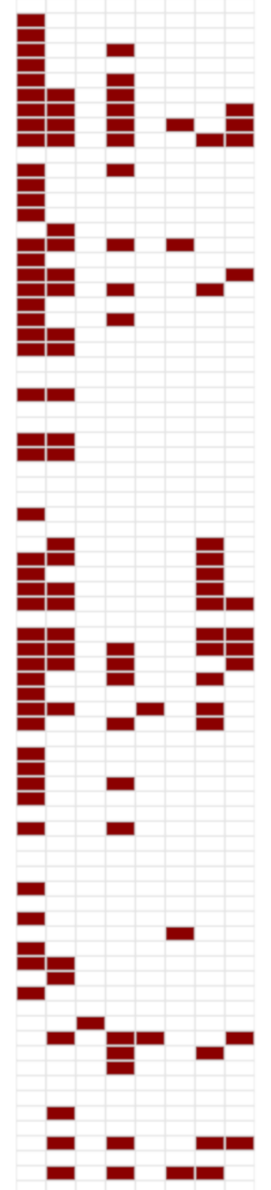

Batadomba Lena_2
Batadomba-Lena-3

$\mathrm{FaHien} C$

Kitulgala $V$
JWP $9 \mathrm{C}$

Batadombā Lena_4

Batadomba tena 5

BuddhaPushkar-A

BuddhaPushkar-C

Pratappur
Batadomba Lena 6
Batadomba Lena 7 a

Batadomba tena

Kitulgala lita

Buddhapushikar E

BuddhaPushkar E-F

BuddhaPushar-
BuddhaPushkar $G$

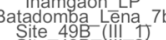

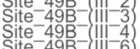

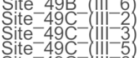

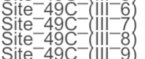

Site-49C-(iil-8

Sagileru 1

Patne $\top$

Patne-1|B

patne-

Patne

Patne-1..1B

Mahadebbera

Sagileru-4

MSV Baghor3a

ISV BaghorFineMember

MSV Dhaba3 Upper

JWP
JWP -2

JWP-21

MSV Dhāba2

Chamu 1

Bhimbetka F23 MP
Bhimbetka MP

Mehtakheri Unit 2

MSV Dhaba3 Lower

Shergärh Trijunction
Katoati S4

Sagileru 2

Shergarh TriJunction 2

Katōati S3b
$16 R$ Dune Sup

Umrethi

MSV Dhaba

Chamu 2 it

Attirampakam $\mathrm{N}^{1}$

WP-3B

Kukdi Bor! Lower

Grit Nr Site 55

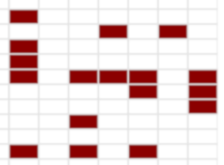

Orsang M

JWP -3

KWP $3 A$

Katoati_S
Karna-1
Karna-2

Karna-3

Orsang A Ach

-

MSV Bamburi 1 SUM

MSV Bamburi_1 1 SLM

MSV Nakihar Knurd SLM

MSV Sihawal II StM

Junagadh (Adi Chadi Wao)

Attirampakam $\mathrm{N2}$
Attirampakam $\mathrm{N} 5 \mathrm{a}$

Kaldevanhall

Attirampakam N3

Attadab 110

Thousand Years Ago

$\begin{array}{llllll}0 & 100 & 200 & 300 & 400 & 500\end{array}$

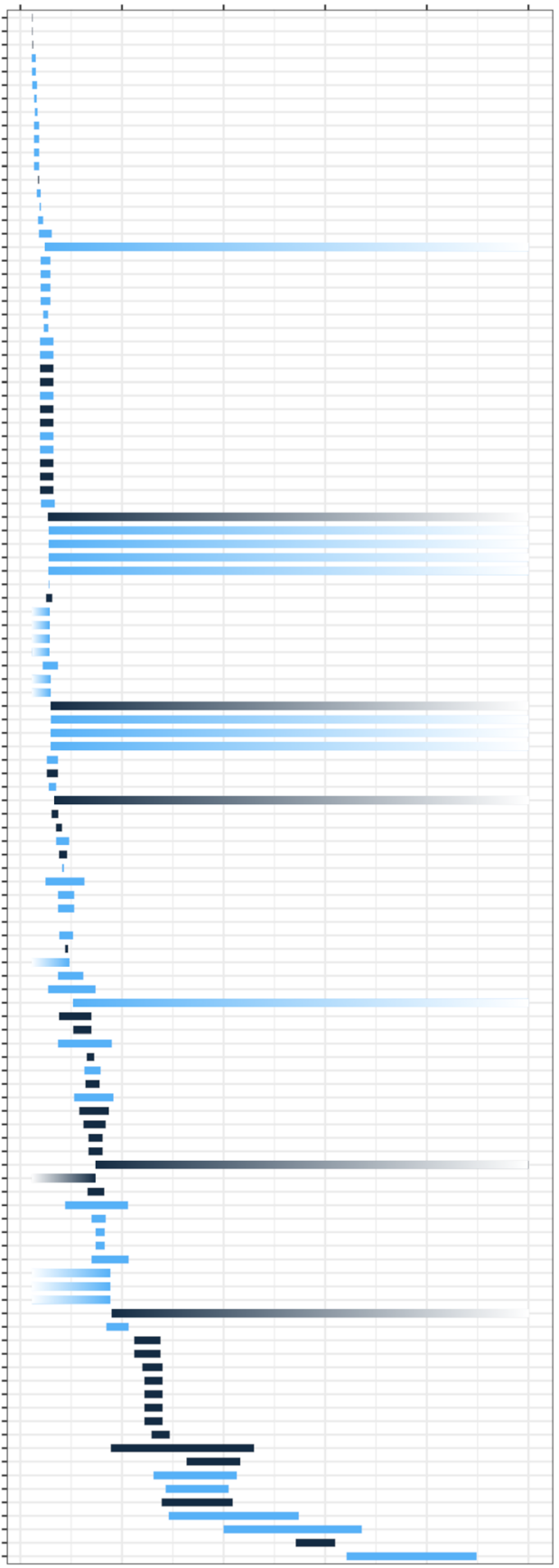


Fig. 1 (left) The presence (red) and absence (white) of stone tool types that may be an index of hafting behaviour (backing, production of point blanks, retouched points, shouldered tools and points, and tanged tools and points) in South Asia Palaeolithic assemblages, with (right) age ranges of each assemblage with hafting indices present (light blue) and absent (dark blue) dating between the mid-Middle Pleistocene and end of the Late Pleistocene (minimum ages fade up to $500 \mathrm{ka}$; maximum ages fade down to $11.5 \mathrm{ka}$ )

\section{Hafting Modifications: Tanged and Shouldered Pieces}

Tanged or shouldered pieces were recognised by Sankalia (1964) in the first definition of Middle Palaeolithic (Middle Stone Age) industries, but it is only recently that they have been recovered from reliably dated Middle Palaeolithic contexts. Two tanged pieces are reported from Attirampakam, dating to $\sim 385 \mathrm{ka}$ and $\sim 175 \mathrm{ka}$ (Akhilesh et al. 2018; Fig. 3b), but are not present in any contemporaneous Late Acheulean assemblages. Shouldered pieces first appear in the oldest horizon at Katoati (Western India) $96 \mathrm{ka}$ (Blinkhorn et al. 2013; Fig. 3b). Diverse shouldered and tanged pieces and points were found at Katoati between 60 and $96 \mathrm{ka}$ (Blinkhorn et al. 2013, 2017), at Chamu between $<58$ and $81 \mathrm{ka}$, at Karna less than $~ 80 \mathrm{ka}$ (Blinkhorn 2014) and less than $74 \mathrm{ka}$ in the Sagileru Valley (Blinkhorn et al. 2014). Two tanged artefacts are known from Jwalapuram 22, $77 \mathrm{ka}$, one of which bears an impact fracture related to use as a hafted tool (Haslam et al. 2012; Fig. 3b). Tanged tools appear less frequently amongst Late Palaeolithic assemblages, though the multiple assemblages at both Patne (Sali 1989) and Buddha Pushkar (Blinkhorn 2018) illustrate their continued use into the terminal Pleistocene.

\section{Hafting Modifications: Backing}

Backing appears a predominately Late Palaeolithic retouching strategy, although rare occurrences are known from the youngest Middle Palaeolithic sites (e.g. Bhimbetka [Misra 1979; Bednarik 2005]). The earliest evidence for Late Palaeolithic backed
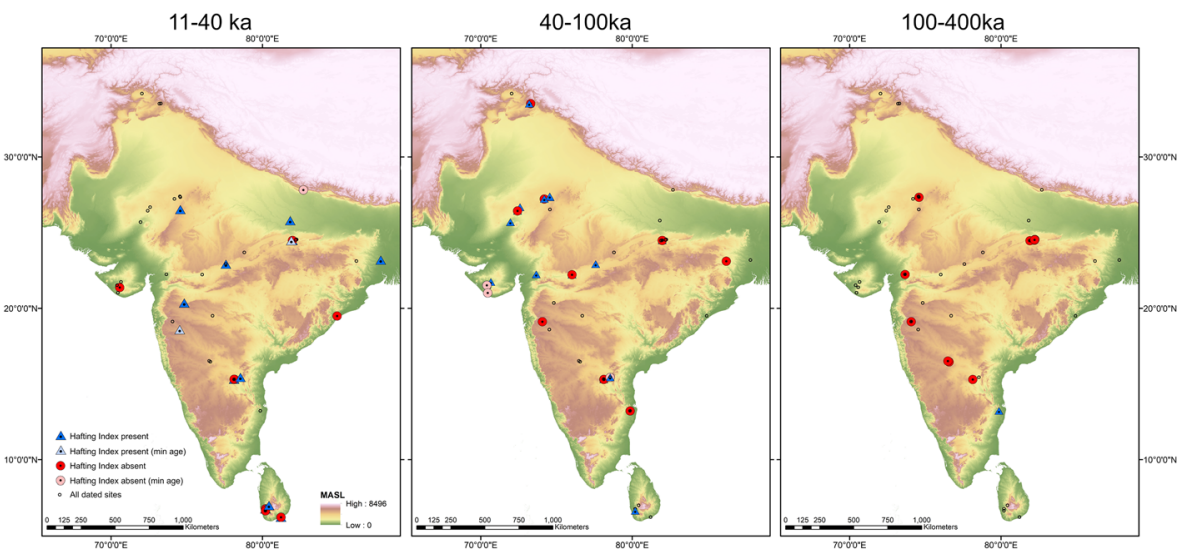

Fig. 2 Maps illustrating the distribution of Palaeolithic sites dating from the mid-Middle Pleistocene $(\sim$ $400 \mathrm{ka}$ ) until the end of the Late Pleistocene, indicating the presence or absence of a stone tool type identified as an index of hafting behaviour (backing, production of point blanks, retouched points, shouldered tools and points, and tanged tools and points) 

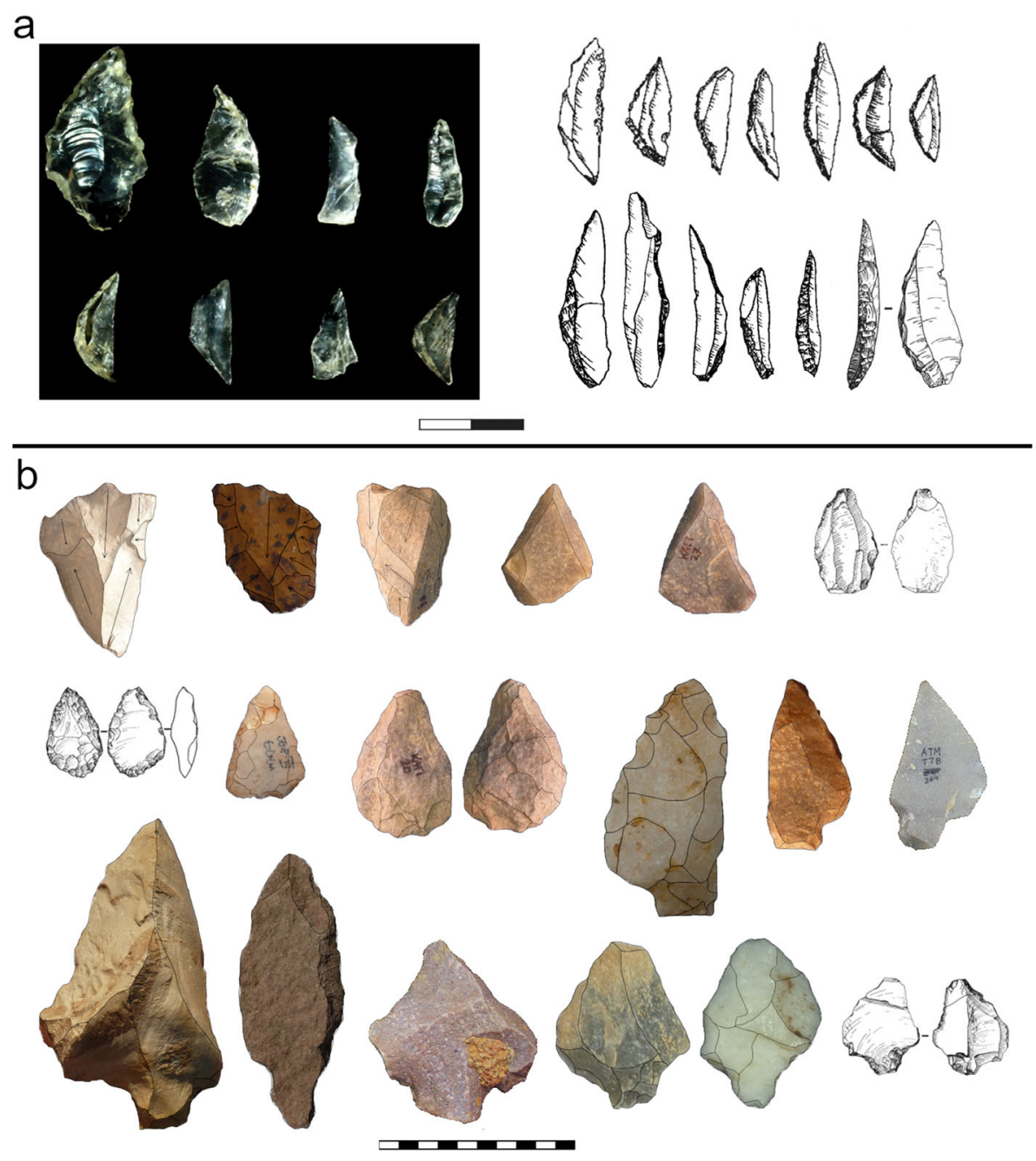

Fig. 3 Examples of lithic types associated with hafting practices from South Asia. a (left) Retouched points (top) and backed artefacts (bottom) from Batadomba Lena (modified from Lewis et al. 2014); (right) backed geometric (top) and non-geometric (bottom) artefacts from Jwalapuram 9 (modified from Clarkson et al. 2009). b Top row, left to right: three-point cores from Shergarh Tri-Junction $(\times 2)$ and Katoati, three Levallois points from Katoati $(\times 2)$ and Jwalapuram 22 (with distal impact fracture; modified form Haslam et al. 2011); middle row: bifacial points from Jwalapuram 22 (modified from Haslam et al. 2011) and Jogpura and Katoati, shouldered points from Sambhar and Katoati, tanged point from Attirampakam (modified from Akhilesh et al. 2018); bottom row: tanged points from Dundar, Chamu and Attiampakam (modified from Akhilesh et al. 2018) and Katoati, Jogpura and Jwalapuram 22 (with distal impact fracture; modified from Haslam et al. 2011)

artefacts appears around $45 \mathrm{ka}$ in both Sri Lanka (Fa Hien [Wedage et al. 2019]) and India (Mehtakheri [Mishra et al. 2013]). Between 25 and $45 \mathrm{ka}$, numerous Late Palaeolithic sites appear with backed artefacts, including recently dated sites such as Mahadebbera (33-45 ka; Basak et al. 2014), Jwalapuram 9 ( 35-12 ka; Clarkson et al. 2009; Fig. 3a), Batadomba Lena (36-28 ka; Fig. 3a), Fa Hien ( 45 ka; Wedage et al. 2019) and Patne (>25 ka; Sali 1989). 


\section{Standardised Point Production}

The appearance of both debitage and façonnage approaches to point production in the Middle Palaeolithic appears a key difference from preceding Late Acheulean technologies (e.g. Sankalia 1964; Blinkhorn et al. 2015). The Attirampakam assemblages (N5, N4, N3) are unique amongst Middle Pleistocene assemblages from South Asia with the reported presence of retouched points (Akhilesh et al. 2018). Retouched points are reported from multiple Middle Palaeolithic assemblages, including Chamu, Jwalapuram 22 (Fig. 3b), Katoati (Fig. 3b) and the Sagileru Valley (Blinkhorn 2014; Blinkhorn et al. 2013, 2014, 2017; Halsam et al. 2011), as well as Late Palaeolithic assemblages such as at Buddha Pushkar, Batadomba Lena and Patne (Blinkhorn 2018; Perera 2010; Sali 1989). The presence of point blanks is more widespread, found not only in the sites yielding retouched points mentioned previously but also in Middle Palaeolithic sites, such as the Orsang Valley, 16R Dune, Site 55 and Bhimbetka (Ajithprasad 2005; Bednarik et al. 2005; Blinkhorn 2013; Dennell et al. 1992; Fig. 3b), and Late Palaeolithic sites, such as Site 49B (Deraniyagala 1992). The presence of point cores is, however, noticeably scarcer, including examples only from Attirampakam, Katoati and Shergarh Tri-Junction (Akhilesh et al. 2018; Blinkhorn 2014; Blinkhorn et al. 2013, 2017; Fig. 3b).

\section{Evaluating the Origins of Hafting in South Asia}

Preliminary evidence for the presence of diagnostic impact fractures on stone points from Jwalapuram 22, $77 \mathrm{ka}$, and on bone points from Fa Hien $\sim 45 \mathrm{ka}$, as well as the presence of mastics on backed pieces from Jwalapuram 9 from $\sim 34$ ka onwards, provides the strongest evidence for the use of hafting in Palaeolithic South Asia. In each case, further analysis is warranted. The presence of macroscopic hafting modifications that serve as indices of hafting is currently the most widespread form of evidence that may document such practices. The isolated appearance of a tanged point and standardised point production reported from the $\sim 385$-ka N5 assemblage from Attirampakam stands out from contemporaneous sites across South Asia, Eurasia and Africa, complicating their interpretation. Similarly, the presence of retouched points, point blanks and a further tanged point in younger assemblages at Attirampakam stands in contrast to other contemporaneous sites in Central (Kaldevanhalli; Sadal), North (Middle Son Valley sites) and West India (16R Dune, Junagadh, Orsang Valley Acheulean). The appearance of these artefacts at Attirampakam could indicate a local innovation of hafting technology, alongside other Middle Palaeolithic technologies. However, such an extraordinary claim, making it amongst the oldest incidences of hafting worldwide, certainly demands functional analyses to support it. If corroborated, such a finding would still be a stark departure from the broader regional pattern of the persistence of Late Acheulean technology and the absence of hafting until at least the end of MIS 6. If this were the case, examining the context of both the appearance and disappearance of hafting technologies alongside their apparent regionality would be critical lines of future inquiry.

Repeated evidence of tanged and shouldered artefacts, both façonnage and debitage approaches to point production, and incidents of impact fractures associated with 
hafting (at Jwalapuram 22) in Middle Palaeolithic assemblages appear from later MIS 5 onwards. The nature of hafting modifications differs in Late Palaeolithic assemblages, appearing from mid-MIS 3 onwards, focusing on backing, including occurrences of hafting mastics identified through residue analysis at Jwalapuram 9. Tool modifications in Middle Palaeolithic assemblages may have enabled hafting methods in which binding was prominent, whereas Late Palaeolithic hafting, and specifically the focus on backing, may be more reliant upon mastic use. Producing mastics that perform predictably may have been a key threshold that enabled the effective use of backed artefacts. Examining changing methods of hafting may therefore be a critical yet unexplored route to explain the Middle to Late Palaeolithic transition.

The paucity of the South Asian fossil record and absence of well-dated, excavated artefact assemblages between $\sim 100$ and $130 \mathrm{ka}$ means that a later/persistent transition to both hafting and Middle Palaeolithic technologies either through local innovation or cultural diffusion cannot readily be differentiated from one another, nor be rejected. Substantial changes in behaviour recorded elsewhere in the world during MIS 5 may also be explained by processes of innovation and diffusion (e.g. East Africa [Blinkhorn and Grove 2018]), and the combination of environmental and population dynamics in South Asia were similarly conducive to both the creation and adoption of new technologies at this time (Blinkhorn and Petraglia 2017). However, the recurrent appearances of indices for hafting behaviour in South Asia during MIS 5 overlap the expansion of modern human populations into the Levant (Grun et al. 2005) and East Asia (Liu et al. 2015) and remain present during MIS 4 during which time, modern humans expanded into South-East Asia (Demeter et al. 2012) and Sahul (Clarkson et al. 2017). These findings are also consistent with genetic records and environmental approaches to the dispersal of modern humans across Southern Asia during MIS 5 (Boivin et al. 2013; Nielsen et al. 2017). The introduction of hafting into South Asia by expanding modern human populations is therefore consistent with this wider body of evidence for the earliest dispersals.

Regardless of how hafting technologies began to be used in South Asia, it is quite startling that their regular use appears to emerge 100 thousand years later than other regions in Africa and Western Eurasia with a comparable Acheulean background. Unlike these comparable regions, South Asia hosts a mosaic of ecologies ranging from xeric plains to montane rainforest, which can often be found in close proximity to one another. Moreover, environmental change, predominately in the form of waxing or waning monsoonal intensity, appears to spatially redistribute these habitats, rather than promote one extreme over the other, marking a notable contrast to the arid landscapes of South-West Asia or the humid forests of South-East Asia (Boivin et al. 2013). Differing human responses to climate change, or patterns of population structuration and inter-population contact within such mosaic ecological communities, may have played a key role in the delayed appearance of hafting technologies in South Asia, with broad implications for understanding the conditions that promote behavioural innovation amongst late Middle Pleistocene hominins, including the earliest Homo sapiens.

Current evidence for the appearance of hafting technology in South Asia may be consistent with its introduction by expanding populations of modern humans. Yet, the appearance of hafting modifications in South Asia, particularly to prominence of tanged and shouldered pieces, is more comparable to North Africa than South-West Asia, despite the latter's presumable importance on eastward routes of expansion. For some, this 
typological discontinuity may present the basis to prefer an independent innovation of hafting in South Asia. An alternative is that expansion into South Asia necessitated new behavioural strategies to engage with changing geological resources (associated with moving from the Eurasian to Indian tectonic plates) and ecological resources (associated with the regions tropical, monsoonal habitats). While abstract reasoning plays a key role in the production of hafted tools (Wynn 2009), deploying these abilities in the face of significant differences in resource base places further demands on human adaptability, for which analogical reasoning may be critical (Wadley 2010). Examining human dispersals through the lens of hafting technology may identify how they were able to adapt to new circumstances so successfully and transcend ecological and demographic boundaries that proved unsurmountable to other hominins. Once more, differentiating local innovation from introduction by expansion of hafting in South Asia may offer new routes to explore broader questions regarding human creativity and cognition.

It grows increasingly clear that the application of functional methods such as use-wear and residue analysis is desperately required in South Asia, not only to identify the earliest evidence of hafting in the region but also to understand how changing hafting practices enabled new means of engagement with the region's ecological mosaic. For instance, changes in hafting methodologies may have enabled development of new stone tool technologies such as the origins of Late Palaeolithic industries, which appear with the earliest evidence for inhabiting the regions rainforests (Wedage et al. 2019). Given the low levels of organic preservation in Palaeolithic sites in the Indian subcontinent, functional studies of hafted tools may provide an important window onto the use of non-lithic resources, opening up questions about the broader ecological engagement of Palaeolithic populations in South Asia. Rather than attempting to divine the origins of hafting in South Asia from an immature dataset, this paper is a call to arms: the origins of hafting is a critical question regarding the cultural evolution of South Asia that has been overlooked despite the wider implications for our global understanding of hominin behaviour.

Acknowledgements The author thanks Prof. Larry Barham for reading an earlier draft of the manuscript and to the McDonald Institute for Archaeological Research, University of Cambridge, for their support. Three anonymous reviewers are thanked for their comments that helped to improve the manuscript. The author is currently supported by the Leverhulme Trust as part of the "Unravelling the pattern, impacts and drivers of early modern human dispersals from Africa” project (Grant Ref: RPG-2017-087).

\section{Compliance with Ethical Standards}

Conflict of Interest The author declares that there is no conflict of interest.

Open Access This article is distributed under the terms of the Creative Commons Attribution 4.0 International License (http://creativecommons.org/licenses/by/4.0/), which permits unrestricted use, distribution, and reproduction in any medium, provided you give appropriate credit to the original author(s) and the source, provide a link to the Creative Commons license, and indicate if changes were made.

\section{References}

Ajithprasad, P. (2005). Early Middle Palaeolithic: a transition phase between the Upper Acheulian and Middle Palaeolithic cultures in the Orsang Valley, Gujarat. Man and Environment, 30, 1-11. 
Akhilesh, K., Pappu, S., Rajapara, H. M., Gunnell, Y., Shukla, A. D., \& Singhvi, A. K. (2018). Early Middle Palaeolithic culture in India around 385-172 ka reframes out of Africa models. Nature, 554(7690), 97101. https://doi.org/10.1038/nature25444.

Athreya, S. (2015). Modern human emergence in South Asia: a review of the fossil and genetic evidence. In Y. Kaifu, M. Izuho, T. Goebel, H. Sato, \& A. Ono (Eds.), Emergence and diversity of modern human behaviour in Paleolithic Asia (pp. 61-79). Texas A\&M University Press.

Bae, C. J., Douka, K., \& Petraglia, M. D. (2017). On the origin of modern humans: Asian perspectives. Science, 358(6368). https://doi.org/10.1126/science.aai9067.

Bar-Yosef, O., \& Kuhn, S. (1999). The big deal about blades: laminar technologies and human evolution. American Anthropologist, 101(2), 322-338. https://oi.org/10.1525/aa.1999.101.2.322/full.

Barham, L. (2013). From hand to handle: the first industrial revolution. Oxford: Oxford University Press.

Basak, B., Srivastava, P., Dasgupta, S., Kumar, A., \& Rajaguru, S. N. (2014). Earliest dates and implications of microlithic industries of Late Pleistocene from Mahadebbera and Kana, Purulia district, West Bengal. Current Science, 107(19), 1167-1171.

Bednarik, R. G., Kumar, G., Watchman, A., \& Roberts, R. G. (2005). Preliminary results of the EIP project. Rock Art Research, 22(2), 147-197.

Blinkhorn, J. (2014). Late Middle Palaeolithic surface sites occurring on dated sediment formations in the Thar Desert. Quaternary International, 350. https://oi.org/10.1016/j.quaint.2014.01.027.

Blinkhorn, J. (2018). Buddha Pushkar revisited: technological variability in Late Palaeolithic stone tools at the Thar Desert margin, India (p. 20). Journal of Archaeological Science: Reports. https://doi.org/10.1016/j.jasrep.2018.04.020.

Blinkhorn, J., Achyuthan, H., Ditchfield, P., \& Petraglia, M. (2017). Palaeoenvironmental dynamics and Palaeolithic occupation at Katoati, Thar Desert, India. Quaternary Research, 87, 298-313. https://doi. org/10.1017/qua.2017.7.

Blinkhorn, J., Achyuthan, H., Petraglia, M., \& Ditchfield, P. (2013). Middle Palaeolithic occupation in the Thar desert during the Upper Pleistocene: the signature of a modern human exit out of Africa? Quaternary Science Reviews, 77. https://doi.org/10.1016/j.quascirev.2013.06.012.

Blinkhorn, J., \& Grove, M. (2018). The structure of the Middle Stone Age of eastern Africa. Quaternary Science Reviews, 195, 1-20. https://doi.org/10.1016/j.quascirev.2018.07.011.

Blinkhorn, J., \& Petraglia, M. D. (2017). Environments and cultural change in the Indian subcontinent: implications for the dispersal of Homo sapiens in the Late Pleistocene. Current Anthropology, 58(S17), S463-S479. https://doi.org/10.1086/693462.

Blinkhorn, J., Smith, V. C., Achyuthan, H., Shipton, C., Jones, S. C., Ditchfield, P. D., \& Petraglia, M. D. (2014). Discovery of Youngest Toba Tuff localities in the Sagileru Valley, south India, in association with Palaeolithic industries. Quaternary Science Reviews, 105. https://doi. org/10.1016/j.quascirev.2014.09.029.

Boëda, E., Bonilauri, S., Connan, J., Jarvie, D., Mercier, N., Tobey, M., et al. (2008). Middle Palaeolithic bitumen use at Umm el Tlel around 70000 BP. Antiquity, 82(318), 853-861. https://doi.org/10.1017/S0003598X00097623.

Boivin, N., Fuller, D. Q., Dennell, R., Allaby, R., \& Petraglia, M. D. (2013). Human dispersal across diverse environments of Asia during the Upper Pleistocene. Quaternary International, 300(0), 32-47. https://doi. org/10.1016/j.quaint.2013.01.008.

Clark, J. D. (1982). The cultures of the middle Palaeolithic/Middle Stone Age. In The Cambridge History of Africa, From Earliest Times to c. 500BC (pp. 248-341). Cambridge: Cambridge University press.

Clarkson, C., Jacobs, Z., Marwick, B., Fullagar, R., Wallis, L., Smith, M., et al. (2017). Human occupation of northern Australia by 65,000 years ago. Nature, 547(7663), 306-310. https://doi.org/10.1038/nature22968.

Clarkson, C., Jones, S., \& Harris, C. (2012). Continuity and change in the lithic industries of the Jurreru Valley, India, before and after the Toba eruption. Quaternary International, 258, 165-179. https://doi. org/10.1016/j.quaint.2011.11.007.

Clarkson, C., Petraglia, M., Korisettar, R., Haslam, M., Boivin, N., Crowther, A., et al. (2009). The oldest and longest enduring microlithic sequence in India: 35000 years of modern human occupation and change at the Jwalapuram locality 9 rockshelter. Antiquity, 83(November 2008), 326-348 http://toba.arch.ox.ac. uk/pub_files/Clarkson2009Antiquity.pdf.

Costa, A. G. (2012). Were there stone-tipped armatures in the South Asian Middle Paleolithic? Quaternary International, 269, 22-30. https://doi.org/10.1016/j.quaint.2011.01.044.

d'Errico, F., \& Banks, W. E. (2013). Identifying mechanisms behind Middle Paleolithic and Middle Stone Age cultural trajectories. Current Anthropology, 54, S371-S387. https://doi.org/10.1086/673388.

Demeter, F., Shackelford, L. L., Bacon, A.-M., Duringer, P., Westaway, K., Sayavongkhamdy, T., et al. (2012). Anatomically modern human in Southeast Asia (Laos) by 46 ka. Proceedings of 
the National Academy of Sciences of the United States of America, 109(36), 14375-14380. https://doi.org/10.1073/pnas.1208104109.

Dennell, R. R. W., Rendell, H. M., Halim, M., Moth, E., Archaeology, F., \& Spring, N. (1992). A 45,000-yearold open-air Paleolithic site at Riwat, Northern Pakistan. Journal of Field Archaeology, 19(1), 17-33.

Deraniyagala, S. U. (1992). The prehistory of Sri Lanka: an ecological perspective. Colombo: Dept. of Archaeological Survey, Govt. of Sri Lanka.

Fairlie, J. E., \& Barham, L. S. (2016). From Chaîne Opératoire to observational analysis: a pilot study of a new methodology for analysing changes in cognitive task-structuring strategies across different hominin tool-making events. Cambridge Archaeological Journal, 26(04), 643-664. https://doi.org/10.1017/s0959774316000469.

Fort, J., Crema, E. R., \& Madella, M. (2015). Modeling demic and cultural diffusion: an introduction. Human Biology, 87(3), 141-149. https://doi.org/10.13110/humanbiology.87.3.0141??

Groucutt, H. S., Scerri, E. M. L., Lewis, L., Clark-Balzan, L., Blinkhorn, J., Jennings, R. P., et al. (2015). Stone tool assemblages and models for the dispersal of Homo sapiens out of Africa. Quaternary International, 382. https://doi.org/10.1016/j.quaint.2015.01.039.

Grun, R., Stringer, C., Mcdermott, F., Nathan, R., Porat, N., Robertson, S., et al. (2005). U-series and ESR analyses of bones and teeth relating to the human burials from Skhul. Journal of Human Evolution, 49, 316-334. https://doi.org/10.1016/j.jhevol.2005.04.006.

Harris, E. E. (2017). Demic and cultural diffusion in prehistoric Europe in the age of ancient genomes. Evolutionary Anthropology, 26(5), 228-241. https://doi.org/10.1002/evan.21545.

Haslam, M., Clarkson, C., Roberts, R. G., Bora, J., Korisettar, R., Ditchfield, P., et al. (2012). A southern Indian Middle Palaeolithic occupation surface sealed by the 74 ka Toba eruption: further evidence from Jwalapuram Locality 22. Quaternary International, 258, 148-164. https://doi.org/10.1016/j.quaint.2011.08.040.

Haslam, M., Roberts, R. G., Shipton, C., Pal, J. N., Fenwick, J. L., Ditchfield, P., et al. (2011). Late Acheulean hominins at the Marine Isotope Stage 6/5e transition in north-central India. Quaternary Research, 75(3), 670-682. https://doi.org/10.1016/j.yqres.2011.02.001.

Higham, T., Jacobi, R., Julien, M., David, F., Basell, L., Wood, R., et al. (2010). Chronology of the Grotte du Renne (France) and implications for the context of ornaments and human remains within the Chatelperronian. Proceedings of the National Academy of Sciences, 107(47), 20234-20239. https://doi. org/10.1073/pnas.1007963107.

Hublin, J., Ben-ncer, A., Bailey, S. E., Freidline, S. E., Neubauer, S., Skinner, M. M., et al. (2017). New fossils from Jebel Irhoud, Morocco and the pan-African origin of Homo sapiens. Nature Publishing Group, 546(7657), 289-292. https://doi.org/10.1038/nature22336.

Inizan, M.-L., Roche, H., \& Tixier, J. (1992). Technology of Knapped Stone. Meudon: CREP.

James, H. V. A. (2011). Becoming human: the emergence of modern human behaviour within South Asia. University of Cambridge.

Kaifu, Y., Izuho, M., \& Goebel, T. (2015). Modern human dispersal and behavior in Paleolithic Asia. In Y. Kaifu, M. Izuho, T. Goebel, H. Sato, \& A. Ono (Eds.), Emergence and diversity of modern human behaviour in Paleolithic Asia (pp. 535-566). Texas A\&M University Press.

Kashyap, A., Yerkes, R., \& Shinde, V. (2009). A pilot use-wear study of lithic tools from the aceramic phase at bagor, Rajasthan, India. South Asian Studies, 25(1), 63-74. https://doi.org/10.1080/02666030.2009.9628699.

Liu, W., Martinon-Torres, M., Cai, Y., Xing, S., Tong, H., Pei, S., et al. (2015). The earliest unequivocally modern humans in southern China. Nature, 526(7575), 696-699. https://doi.org/10.1038/nature15696.

Lombard, M. (2005). Evidence of hunting and hafting during the Middle Stone Age at Sibidu Cave, KwaZuluNatal, South Africa: a multianalytical approach., 2004. https://doi.org/10.1016/j.jhevol.2004.11.006.

Mathpal, Y. (1985). The hunter-gatherer way of life depicted in the Mesolithic rock paintings of Central India. In V. N. Misra \& P. Bellwood (Eds.), Recent advances in indo-Pacific prehistory (pp. 117-184). Leiden: Brill.

Mazza, P. P. A., Martini, F., Sala, B., Magi, M., Colombini, M. P., Giachi, G., et al. (2006). A new Palaeolithic discovery: tar-hafted stone tools in a European Mid-Pleistocene bone-bearing bed. Journal of Archaeological Science, 33(9), 1310-1318. https://doi.org/10.1016/j.jas.2006.01.006.

Mellars, P., Gori, K. C., Carr, M., Soares, P. A., \& Richards, M. B. (2013). Genetic and archaeological perspectives on the initial modern human colonization of southern Asia. Proceedings of the National Academy of Sciences of the United States of America, 110, 10699-10704. https://doi.org/10.1073/pnas.1306043110.

Mishra, S., Chauhan, N., \& Singhvi, A. K. (2013). Continuity of microblade technology in the Indian subcontinent since $45 \mathrm{ka}$ : implications for the dispersal of modern humans. PLoS One, 8(7), e69280. https://doi.org/10.1371/journal.pone.0069280.

Murty, M. L. K. (1981). Hunter-gatherer ecosystems of subsistence behaviour patterns an of India: coast archaeological. World Archaeology, 13(1), 47-58.

Murty, M. L. K. (1985). Ethnoarchaeology of the Kurnool Cave areas, South India. World Archaeology, 17(2), 192-205. 
Nielsen, R., Akey, J. M., Jakobsson, M., Pritchard, J. K., Tishkoff, S., \& Willerslev, E. (2017). Tracing the peopling of the world through genomics. Nature, 541, 302-310. https://doi.org/10.1038/nature21347.

Patnaik, R., Chauhan, P. R., Rao, M. R., Blackwell, B. A. B., Skinner, A. R., Sahni, A., et al. (2009). New geochronological, paleoclimatological, and archaeological data from the Narmada Valley hominin locality, central India. Journal of Human Evolution, 56(2), 114-133. https://doi.org/10.1016/j.jhevol.2008.08.023.

Pawlik, A. (2011). Have we overlooked something? Hafting traces and indications of modern traits in the Philippine Palaeolithic. Bulletin of the Indo-Pacific Prehistory Association, 30(0), 35-53. https://doi. org/10.7152/bippa.v30i0.12029.

Perera, N. (2010). Prehistoric Sri Lanka: Late Pleistocene rockshelters and an open-air site. Oxford: BAR Publishing.

Perera, N., Kourampas, N., Simpson, I. A., Deraniyagala, S. U., Bulbeck, D., Kamminga, J., et al. (2011). People of the ancient rainforest: Late Pleistocene foragers at the Batadomba-lena rockshelter, Sri Lanka. Journal of Human Evolution, 61(3), 254-269. https://doi.org/10.1016/j.jhevol.2011.04.001.

Petraglia, M., Korisettar, R., Boivin, N., Clarkson, C., Ditchfield, P., Jones, S., et al. (2007). Middle Paleolithic assemblages from the Indian subcontinent before and after the Toba super-eruption. Science (New York, N.Y.), 317(5834), 114-116. https://doi.org/10.1126/science.1141564.

Rots, V. (2013). Insights into early Middle Palaeolithic tool use and hafting in Western Europe. The functional analysis of level IIa of the early Middle Palaeolithic site of Biache-Saint-Vaast (France). Journal of Archaeological Science, 40, 497-506.

Rots, V. (2016). Projectiles and hafting technology. In R. Iovita \& K. Sano (Eds.), Multidisciplinary approaches to the Study of Stone Age weaponry (pp. 167-185). Dordrecht: Springer. https://doi.org/10.1007/978-94-017-7602-8.

Rots, V., \& Van Peer, P. (2006). Early evidence of complexity in lithic economy: core-axe production, hafting and use at Late Middle Pleistocene site 8-B-11. Sai Island (Sudan), 33, 360-371. https://doi.org/10.1016/j. jas.2005.08.002.

Rots, V., \& Plisson, H. (2014). Projectiles and the abuse of the use-wear method in a search for impact. Journal of Archaeological Science, 48, 154-165. https://doi.org/10.1016/j.jas.2013.10.027.

Sali, S. (1989). The Upper Palaeolithic and Mesolithic cultures of Maharashtra. Pune: Deccan College, PostGraduate and Research Institute.

Shea, J. J. (1993). Lithic use-wear evidence for hunting by Neanderthals and early modern humans from the Levantine Mousterian. Archeological Papers of the American Anthropological Association, 4(1), 189197. https://doi.org/10.1525/ap3a.1993.4.1.189.

Shipton, C. (2016). Hierarchical organization in the Acheulean to middle Palaeolithic transition at Bhimbetka, India. Cambridge Archaeological Journal, 26, 601-618. https://doi.org/10.1017/S095977431600041X.

Shipton, C., Clarkson, C., Pal, J. N., Jones, S. C., Roberts, R. G., Harris, C., et al. (2013). Generativity, hierarchical action and recursion in the technology of the Acheulean to Middle Palaeolithic transition: aperspective from Patpara, the Son Valley, India. Journal of Human Evolution, 65(2), 93-108. https://doi. org/10.1016/j.jhevol.2013.03.007.

Shumaker, R. W., Walkup, K. R., \& Beck, B. B. (2011). Animal tool behaviour: the use and manufacture of tools by animals. JHU Press.

Tomasso, S., \& Rots, V. (2018). What is the use of shaping a tang? Tool use and hafting of tanged tools in the Aterian of northern Africa. Archaeological and Anthropological Sciences, 10(6), 1389-1417. https://doi. org/10.1007/s12520-016-0448-3.

Wadley, L. (2010). Compound-adhesive manufacture as a behavioral proxy for complex cognition in the Middle Stone Age. Current Anthropology, 51(s1), S111-S119. https://doi.org/10.1086/649836.

Wedage, O., Amano, N., Langley, M. C., Douka, K., Blinkhorn, J., Crowther, A., et al. (2019). Specialized rainforest hunting by Homo sapiens $\sim 45,000$ years ago. Nature Communications, 10, 739. https://doi. org/10.1038/s41467-019-08623-1.

Wilkins, J., \& Schoville, B. J. (2016). Multidisciplinary approaches to the study of Stone Age weaponry, 101117. https://doi.org/10.1007/978-94-017-7602-8.

Wilkins, J., Schoville, B. J., Brown, K. S., \& Chazan, M. (2012). Evidence for early hafted hunting technology. Science, 338, 942-946. https://doi.org/10.1126/science.1227608.

Wynn, T. (2009). Hafted spears and the archaeology of mind. Proceedings of the National Academy of Sciences of the United States of America, 106(24), 9544-9545. https://doi.org/10.1073/pnas.0904369106.

Zipkin, A. M., Wagner, M., McGrath, K., Brooks, A. S., \& Lucas, P. W. (2014). An experimental study of hafting adhesives and the implications for compound tool technology. PLoS One, 9(11), e112560. https://doi.org/10.1371/journal.pone.0112560.

Publisher's Note Springer Nature remains neutral with regard to jurisdictional claims in published maps and institutional affiliations. 